\title{
Coral Infantil da UFRJ: do Sacro ao Profano
}

\section{Children's Choir from UFRJ: from Sacred to Profane}

DOI: $10.46814 /$ lajdv2n5-012

Recebimento dos originais: 10/07/2020

Aceitação para publicação: 30/08/2020

\section{Maria José Chevitarese}

Doutora em Psicossociologia de Comunidade e Ecologia Social pela Universidade Federal do Rio de Janeiro -UFRJ/ Instituto de Psicologia

Instituição: Escola de Música da Universidade Federal do Rio de Janeiro -UFRJ/ Escola de Música Endereço: Rua do Passeio, 98 - Centro, Rio de Janeiro - RJ, Brasil

E-mail: zezechevitarese@gmail.com

\section{Ana Claudia Reis}

Doutora em Música (Processos Criativos) pela Universidade Federal do Rio de Janeiro -UFRJ/Escola de Música

Instituição: Secretaria Municipal de Educação- Prefeitura Municipal de Duque de Caxias- RJ

Endereço: R. Pref. José Carlos Lacerda, 1424 - Jardim Vinte e Cinco de Agosto, Duque de Caxias RJ- Brasil

E-mail: claussreis@gmail.com

\section{RESUMO}

A música coral tem se mostrado, ao longo dos tempos, um excelente instrumento no processo de musicalização tanto de crianças como de adultos, independentemente do grau de conhecimento ou desenvolvimento musical e da maior ou menor facilidade. Dentro deste contexto foi idealizado o Coral Infantil da UFRJ, projeto de extensão universitária que tem como proposta ser ao mesmo tempo um coro inclusivo e coro de concerto. A escolha do repertório faz parte da estratégia de ação do projeto e do processo de musicalização do grupo.

Palavras-chave: coral infantil, repertório coral.

\begin{abstract}
Choral music has, over time, been an excellent instrument in the musicalization process for both children and adults, regardless of the degree of musical knowledge or development and the greater or lesser ease. Within this context, the Children's Choir from UFRJ was conceived, a university extension project that aims to be both an inclusive choir and a concert choir. The choice of repertoire is part of the project's action strategy and the group's musicalization process.
\end{abstract}

Keywords: children's choir, choral repertoire. 


\section{INTRODUÇÃO}

O canto coletivo é por excelência uma atividade cultural capaz de articular diferenças em prol do coletivo, tendo sido utilizado nos mais diferentes contextos. Ao estudar o canto coletivo no Brasil verifica-se que essa prática se manteve presente ao longo de toda nossa história, embora tenha vivido momentos com total apoio do estado e outros com ausência do mesmo (CHEVITARESE, 2007, p. 26 -40). A música coral tem se mostrado, ao longo dos tempos, um excelente instrumento no processo de musicalização, independentemente do grau de conhecimento ou desenvolvimento musical e da maior ou menor facilidade dos cantores no que se refere à compreensão do texto musical. A música coral oferece uma vivência musical não apenas a um reduzido número de pessoas ditas "bem-dotadas" ou "talentosas", mas a um universo bem mais amplo.

Em relação ao repertório concordamos com Vertamatti:

Entendendo o coro como processo educacional, ou seja, que a prática vocal é uma forma de desenvolvimento do jovem e da criança, acredita-se que a linguagem musical deva ser apresentada e vivenciada em ampla diversidade com seus vários estilos e modalidades, seja tonal, modal, atonal ou eletroacústica. (VERTAMATTI, 2007, p. 17)

Como professora da Universidade Federal do Rio de Janeiro, encontrei na extensão universitária o espaço ideal para o desenvolvimento da atividade coral com crianças e jovens tomando como um dos eixos de trabalho a diversificação do repertório. O coro funciona como um instrumento de musicalização infanto-juvenil e um espaço de reflexão e desenvolvimento de pesquisas realizadas em conjunto com os alunos dos cursos de licenciatura, bacharelado e pós-graduação em música.

O Coral Infantil da Universidade Federal do Rio de Janeiro, projeto de extensão universitária, foi criado em 1989 e vem trabalhando de forma ininterrupta desde então. Tem como objetivo o desenvolvimento vocal e musical de crianças e jovens na faixa etária de 7 a 15 anos e a preparação de solistas para atuar em óperas e concertos sinfônicos.

\section{O CORAL INFANTIL DA UFRJ}

O Coral Infantil da Universidade Federal do Rio de Janeiro tem como proposta ser ao mesmo tempo um coro inclusivo e um coro de concerto. Ao entrar para o grupo, não é exigido que a criança possua um determinado nível de desenvolvimento vocal nem conhecimento musical prévio. A única avaliação feita é em relação à classificação vocal para que possamos determinar em que naipe esta criança será inserida. Os cantores são classificados como sopranos, mezzo-soprano e contralto. O grupo, que ensaia quatro horas semanais, inicia seus ensaios por aquecimento vocal e além disso têm 
aulas de técnica vocal individual ou em pequenos grupos. Atualmente, esta preparação vocal é realizada pela aluna do Bacharelado em Música - habilitação canto, Beatriz Simões.

Do currículo do coro constam mais de 400 apresentações em salas de concerto do Rio de Janeiro e Minas Gerais, São Paulo, Buenos Aires e Argentina. O grupo já participou da montagem de diversas óperas, sinfonias, cantatas e outras obras. Destacamos abaixo algumas das participações mais significantes.

\begin{tabular}{|c|c|}
\hline Compositores & Obras \\
\hline Giacomo Puccini & Tourandot, La Bohème e Tosca \\
\hline Georges Bizet & Carmem \\
\hline Engelbert Humperdinck & Hansel und Gretel \\
\hline Arrigo Boito & Mefistófoles \\
\hline Wolfgang Amadeus Mozart & A Flauta Mágica \\
\hline Giuseppe Verdi & Macbeth \\
\hline Villa-Lobos & O Menino Maluquinho \\
\hline Ernani Aguiar & Carmina Burana \\
\hline Carl Orff & $3^{\text {a Sinfonia }}$ \\
\hline Gustav Mahler & Te Deum \\
\hline Hector Berlioz & On the Transfigurations of Souls \\
\hline John Adams & War Requiem e Billy Budd \\
\hline Benjamin Britten & \\
\hline
\end{tabular}

Em 2010, o Coral Infantil da UFRJ atuou nas comemorações do Bi-centenário da Independência da Argentina, realizando concertos em Buenos Aires. Em 2011 participou da estreia mundial da ópera Juca, Joca e o pé de jaca de Rafael Bezerra e em 2013 do musical Godó, o bobo alegre, de Francisco Mignone com texto de Pedro Bloch (estreia mundial). Em 2014 participou da montagem de O Pequeno Príncipe com música e regência de Glauco Fernandes, no Theatro Municipal do Rio de Janeiro. Em 2015 participou da obra Mandu Çarará de Villa-Lobos, com coro e orquestra do mesmo teatro, sob a regência de Isaac Karabtchevsky.

\section{EM RELAÇÃO À FAIXA ETÁRIA}

Grupos infantis, que abrangem a faixa etária entre 7 e 15 anos são geralmente heterogêneos com uma larga gama de amadurecimento vocal e individual. Concordamos com Bochniak (1992), quando afirma que a condução de um trabalho artístico pode ser desenvolvida quando estamos dispostos a romper barreiras entre teoria e prática, obrigação e satisfação, produzindo ou reproduzindo conhecimento, mesmo trabalhando com grupos heterogêneos. No caso do Coral Infantil da UFRJ as crianças mais novas são colocadas nas fileiras mais à frente e as mais velhas nas fileiras posteriores. Assim a voz dos mais velhos, geralmente mais antigos no coro e, por conseguinte mais 
experientes, funciona como exemplo vocal e guia para os novos cantores que rapidamente se entrosam no grupo.

\section{DO REPERTÓRIO}

A escolha do repertório a ser trabalhado em um coro está intrinsecamente ligada à sua identidade. No caso do Coral Infantil da UFRJ, o repertório adotado faz parte de uma estratégia que visa a ampliação do universo cultural de nossos cantores. Procuramos adotar um repertório passando pelos diversos estilos, épocas e compositores. Ao longo desses 26 anos de trabalho o repertório procurou englobar música popular brasileira, música folclórica nacional e internacional, canções nacionais, canções tradicionais internacionais, obras corais de compositores brasileiros e estrangeiros, óperas e repertório sinfônico que faz uso de coro infantil. Acreditamos ser importante incentivar os cantores a entrar em contato com novos repertórios, estéticas, culturas, línguas e combinações sonoras para que ampliem seu universo cultural, linguístico e perceptivo. De acordo com Small, "tomar parte de diferentes tipos de musicar é olhar para diferentes tipos de relações e não se pode projetar as normas de um tipo de performance para um outro tipo" (SMALL, 1995, p. 10). Desta forma cada obra a ser estudada é contextualizada para que haja a compreensão da peça e se possa construir, em conjunto com o grupo uma interpretação.

Figueiredo, chama a atenção para a necessidade do treinamento para que os cantores tenham um conjunto de condições mínimas para a realização musical. $\mathrm{O}$ autor defende que esse treinamento deve ser feito sob base sólida de forma que promova aprendizagem e não um simples adestramento e possibilite a transferência dos conteúdos assimilados para novas situações (FIGUEIREDO, 1989, p. 74-75). O ensaio não poderá ser um local de mera imitação e sim um lugar de trocas de experiências, diálogo e construção de novos conhecimentos.

\section{DO CONCERTO}

De acordo com Vertamatti "crianças e jovens devem ser expostos a uma imensa gama de experiência musicais, incluindo cantos em idiomas estrangeiros, ruídos, organizações não-tonais e outros" (VERTAMATTI, 2007, p. 39). É importante que corais infanto-juvenis trabalhem diferentes tipos e gêneros musicais de modo a terem oportunidade de vivência ampla e diversificada. $\mathrm{O}$ repertório proposto para este concerto também seguiu este direcionamento. A primeira parte do 
Lord have mercy upon us Oh, Lord, grant us mercy, Peace and charity, Love and honesty Oh, Lord, give us hope.

Clare Benediction tem música e letra de John Rutter. A peça é escrita para três vozes iguais, com acompanhamento de piano. A peça inicia-se em uníssono com soprano seguido de contralto, e logo após um tutti, trazendo um interessante efeito devido à diferença de timbres infantis. A seguir a peça abre em três vozes e caminha desta forma até o final da peça. Seu texto nos diz:

May the Lord show his mercy upon you; May the light of his presence be your guide: May he guard you and uphold you; May his spirit be every by your side.

When you sleep, may his angels watch over you; When you wake, may he fill you with his grace: May you love him and serve him all your days,

Then in heaven may you see his face.

May the Lord's loving kindness surround you; Keep you safe as you journey on your way: May he lead you and inspire you As he grants you the gift of each new day.

May he bless all your loved ones and cherish them; Every friend, every stranger at your door: In the name of his Son, our Saviour Christ, May God bless you, now and evermore.

A segunda parte do programa é constituída por peças folclóricas do Brasil, Nova Zelândia, México e Estados Unidos. As obras são todas cantadas em seu idioma original, fazendo com que os pequenos cantores entrem em contato com outras línguas e culturas. Estas canções folclóricas

\footnotetext{
${ }^{1}$ Educadora musical americana, especialista em Kodaly que trabalha junto a equipe do Indianapolis's Choir.

${ }^{2}$ Organista americano, pianista e arranjador. Trabalha junto à equipe do Indianapolis's Choir.

${ }^{3}$ Compositor contemporâneo inglês, nascido em 24 de setembro de 1945.
} 
brasileiras têm arranjos de Villa-lobos (1887-1959), compositor e maestro brasileiro de grande importância para implantação do canto orfeônico no Brasil. Embora a prática do canto orfeônico já existisse em São Paulo nos anos 1910-1920, "a versão que se tornou referência para todo país foi a de Villa-Lobos, implantada nas escolas com a promulgação do Decreto $\mathrm{n}^{\circ} 19.890$ de 18-04-1931 (Reforma Francisco Campos), visando alcançar, a partir do Distrito Federal, todo o território nacional" (SANTOS, 2011, p.168).

Tutira Mai, é uma canção tradicional Maori, tribo da Nova Zelândia que diz:

Tutira mai nga iwi, tatou, tatou e. Tutira mai nga iwi, tatou, tatou e.

Whaia te maramatanga, me te aro ha. Enga $i$ wi kia tapatahi, kia kotahi ra, tatou, tatou e.

Segue-se a peça La cucaracha, folclore mexicano com arranjo do maestro e compositor espanhol Alberto Grau (1937), nascido em Barcelona e radicado na Venezuela. A música tem uma introdução sob o texto: Es que ella no tiene la principal, com entradas sucessivas iniciando pela voz mais aguda, seguida da voz intermediária e finalizando com a entrada da voz mais grave. Segue-se a peça a três vozes com o texto:

Dicen que la cucaracha tuvo unos gemilitos A los cuales ella llama Bonifacio y Angelito.

Dicen que la cucaracha fué muy buena bailadora

Pero com su pata rota ya no baila ni la jota.

La cucaracha, la cucaracha ya no puede caminhar Porque no tiene, porque le falta la patica principal.

La cucaracha cayo de una bicicleta

$Y$ por eso su patica No puede calzar chacleta.

Dicen que la cucaracha Ya no puede caminhar! 
Terminamos esta seção com o negro spiritual Little David, Play on your harp, com arranjo de Rollo Dilworth (educador musical americano). O negro spiritual é um gênero musical que surgiu com os escravos no sul dos Estados Unidos. Muitos deles são canções de cunho religioso como a que apresentaremos neste concerto que conta a história de David que matou o gigante Golias. Seu texto nos diz:

\author{
Little David, play on his harp,
Hallelu, hallelu; \\ Little David, play on his harp,
Hallelu, hallelu; \\ Little David was a shepherd boy, \\ He killed Goliath and shouted for joy. \\ Old Joshua was the son of Nun \\ He never would quit 'til his work was done. \\ David played, he danced and sang \\ All day 'til the heaven rang, \\ Singin' songs of joy and praise, \\ David played his harp for the rest of his days.
}

O programa finaliza com três canções em português: O alfabeto, atribuída a Mozart (17561791), Quem mora?, de Denise Mendonça, com arranjo de Elza Lakchevitz (1932) e Pensando em namorar, um pout pourri de canções de Luiz Gonzaga (1912-1989), compositor nordestino conhecido como Rei do Baião, com arranjo de Cezar Elbert.

\title{
Música Sacra:
}

Kyrie

A Clare Benediction

\section{Música Folclórica:}

Que lindos olhos!

Nesta Rua

O limão

Tutira Mai

Arr: Anthony Ritckie

La cucaracha

Little David, Play on your harp
Ruth E. Dwyer e Martin L. Ellis

Jonh Rutter

Folclore Brasileiro

Arr: Villa-Lobos

Tradicional Maori (Nova Zelândia)

Popular Mexicano

Arr: Alberto Grau

Spiritual

Arr: Rollo Dilworth 


\section{Música Profana:}

$\begin{array}{ll}\text { Alphabeto } & \text { Mozart } \\ \text { Quem Mora? } & \text { Poema Maria Mazzeti } \\ & \text { Música Denise Mendonça } \\ & \text { Arr: Elza Lakschevitz } \\ \text { Pensado em namorar } & \text { Luiz Gonzaga } \\ & \text { Arr: Cezar Elbert }\end{array}$

\section{REFERÊNCIAS}

BOCHNIAK, Regina. Questionar o conhecimento: interdisciplinaridade na escola ... e fora dela. São Paulo: Loyola, 1992.

CHEVITARESE, Maria José. O Canto Coral como Agente de transformação Sociocultural nas Comunidades do Cantagalo e Pavão-Pavãozinho: Educação para Liberdade e Autonomia. Tese de doutorado apresentada no Programa EICOS de Pós-Graduação em Psicossociologia de Comunidades e Ecologia Social, Instituto de Psicologia da UFRJ, 2007.

FIGUEIREDO, Sérgio Luiz Ferreira. A função do ensaio coral: treinamento ou aprendizagem? In: Revista Opus 1, volume 1.p.72-78, 1989.

SANTOS, Regina Marcia Simão. Música, Cultura e Educação, Porto Alegre: Editora Sulina, 2011.

SMALL, Christopher. Musicking: A Ritual in Social Space. In: RIDEOUT, Roger (ed.) On The Sociology of Music Education. University of Oklahoma, p. 1-12, 1995.

VERTAMATTI, Leila Rosa Gonçalves. Ampliando o repertório do coro infanto-juvenil: Um estudo de repertório inserido em uma nova estética, Editora Unesp, 2007. 